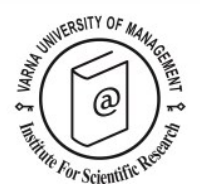

\title{
Dawning of the Age of Robots in Hospitality and Tourism: Challenges for Teaching and Research
}

\author{
Jamie Murphy ${ }^{1 *}$, Charles Hofacker ${ }^{2}$ and Ulrike Gretzel ${ }^{3}$
}

Received: 12/11/2016 Accepted: 08/12/2016

\footnotetext{
${ }_{1}^{1}$ Australian School of Management, Email: jamie.perth@gmail.com

2 Florida State University, Email: chofacker@fsu.edu

${ }^{3}$ University of Southern California, Email: Gretzel@usc.edu

* Corresponding author
}

\begin{abstract}
This conceptual paper revisits, refreshes and reinforces a 1984 study that challenged hospitality educators to include robotics in their classes and their research. The paper briefly reviews robotics literature, explains three robot categories-industrial, professional service and personal serviceemphasises the importance of autonomy and human robot interaction, and provides hospitality and tourism examples. This literature review leads to six areas of importance for teaching and research of robotics in hospitality and tourism. The paper gives academics and practitioners a foundation for envisioning the current and future state of robots in hospitality and tourism.
\end{abstract}

@ 2017 Varna University of Management. All rights reserved

Keywords: robots, robotics, human robot interaction, autonomy

Citation: Murphy, J., C. Hofacker, U. Gretzel (2017) Dawning of the Age of Robots in Hospitality and Tourism: Challenges for Teaching and Research. European Journal of Tourism Research 15 pp. 104-111

\section{Introduction}

Over three decades ago, Collier (1983) heralded the demise of the industrial revolution at the hands of robotics and computerised manufacturing. His examples included pneumatic delivery, automated teller machines, phone answering machines and automated hotel elevators. His prediction of a 32-hour work week by 2000 , alas, has yet to come true in most countries.

Much work across diverse areas examines the diffusion-that is, the adoption and implement- tation-of new technology at both the organisational and individual level (Rogers, 2003). For example, one early conceptual framework addressing diffusion at the individual level suggested the less advanced the technology, the higher the customer contact (Walley \& Amin, 1994). The authors noted that vending machines were low technology but high customer contact. A travel agency IT system however, had high technology but the customer had no capability for direct contact with that technology. 
Research in service marketing, such as travel IT system interfaces, has been particularly concerned with technology diffusion and its impact on customers (see Kim, Wang, \& Malthouse, 2015; Lam \& Shankar, 2014 for two recent examples). Service scholars developed the paradigm of eService-providing customer service over electronic networks (Rust \& Kannan, 2003, p. 38) -and its impact on the customers (e. g., Collier \& Bienstock, 2006; Fassnacht \& Koese, 2006; Parasuraman, Zeithaml, \& Malhotra, 2005). Almost all eService studies, whether looking at adoption or implementation, focus on software that runs on an inert device such as a desktop computer or a mobile phone. Little in the tourism and hospitality literature or for that matter the service literature in general, examines service delivered by robotic devices.

Why should a science fiction phenomenon, which most probably lies only at the margin of today's economy, concern tourism and hospitality academics? In their book The Second Machine Age, Brynjolfsson, McAfee and Cummings (2014) underscore that information technology cost effectiveness increases exponentially. The capabilities in the simple robots of today will double, and double again every couple of years, assuming that Moore's Law remains in force. Artificial intelligence, sensing, actuator and power technology advances should fuel a robotics explosion comparable to what microprocessors did for computing three decades ago (Touretzky, 2010).

A year after Collier's (1983) predictions, a study challenged hospitality educators to consider advanced technology, particularly robots, in their classes and their research (Andrew, 1984). Scholars should examine customer acceptance of robots in foodservice and robots' impacts on the work environment, management training, facility design and bottom line. The objective of this manuscript is to nudge hospitality and tourism academics, again, to think about the applications and subsequent implications of robot delivered service. As such, the paper begins with an overview of the robotics literature, followed by a renewed and extended challenge to hospitality and tourism academics to consider robotics in their classes and research.

\section{Literature Review}

The Rise of the Robots

The industrial age, science fiction books in the 1800 s, and a play in the early 1900 s laid the groundwork for the modern concept of robots. Mary Shelley's novel Frankenstein, first published anonymously in 1818, conjured gruesome images of combining body parts into a sentient being. Half a century later, Jules Verne introduced a steam-powered mechanical elephant in The Steam House. Then in 1921, the Czech Karel Čapek's (2001) play Rossum's Universal Robots introduced the term 'robot'robuta in Czech, translated as forced laborand the eventual extinction of the human race at the hands of robots.

Today, robotic applications abound in manufacturing, inside and outside the home, medicine, entertainment, the military and law enforcement and various other applications (Thrun, 2004; Vaussard et al., 2014). Toy manufacturer Lego has built robot-like features into many of its products, and robot competitions-for instance navigating a restaurant or delivering food orders-are emerging (Angulo, Pfeiffer, Tellez, \& Alenyà, 2015; Touretzky, 2010). Within the extant economy, robots are now routine in military and law enforcement applications (Calderone, 2013; Swinson, 1997) and health care delivery (Ackerman, 2014; Blackman, 2013; Kavic, 2004; Oborn, Barrett, \& Darzi, 2011). A burgeoning application is robots interacting with the elderly (Flandorfer, 2012; Glende, Conrad, Krezdorn, Klemcke, \& Krätzel, 2015; J. Lam, 2015).

Robots are also surfacing in hospitality and tourism. A restaurant in China has introduced robot waiters (BBC, 2014), Japan has a robot hotel (Martin, 2016) and is testing robotic information agents (Pan, Okada, Uchiyama, \& Suzuki, 2015). Robotic floor cleaners are approaching a mature product category (Sung, Grinter, Christensen, \& Guo, 2008; Touretzky, 2010; Vaussard et al., 2014) and assisted ambient living services-e.g. home-care and smart homes-keep improving (Angulo et al., 2015). 
Pondering his creation, the father of robotics Joseph Engelberger stated, "I can't define a robot, but I know one when I see one (Beer, Fisk, \& Rogers, 2012, p. 9)." Definitions for robots vary (Beer et al., 2012; Oborn et al., 2011; Thrun, 2004; Vaussard et al., 2014) and this paper defines robots simply as a "relatively autonomous physical device capable of motion and performing a service." Furthermore, an important question is not what can a robot do, rather what should a robot do, and to what extent (Beer et al., 2012). Finally, the role of autonomy and Human Robot Interaction (HRI), critical to the abstract notion of a robot, help clarify the concept of robots across three broad categories of application-industrial, professsionnal service and personal service (Beer et al., 2012; Thrun, 2004; Vaussard et al., 2014).

\section{Autonomy and Categorising Robots}

In categorising robots, it is important to distinguish between devices that make decisions with or without human input, a continuum respectively ranging from quasiautonomous to autonomous (Beer et al., 2012; Swinson, 1997; Thrun, 2004). Quasiautonomous robot decisions stem either from their programming (think automatic dishwasher) or from a remote human operator (think drone controlled with a joy stick). Thanks to programming and artificial intelligence, fully autonomous robots exhibit agency-the ability to accommodate environmental variations without further input (Thrun, 2004). "Developing fully autonomous robots has been a goal of roboticists and other visionaries since the emergence of the field, both in product development and science fiction" (Beer et al., 2012, p. 7).

Autonomy opens the door to rich social humanrobot interactions such as awareness, trust and acceptance (Beer et al., 2012). Yet such social interaction is a double-edged sword (Thrun, 2004). Designing improved human-robot interfaces is possible by exploiting familiar social rules and conventions, which may lead to people attributing capabilities that do not exist into robotic technology such as in the movie 'Robot and Frank.' Do "we ever want to interact with robots the same way we interact with our next-door neighbor, our colleagues, or with the people who work in our homes (Thrun, 2004, pp. 10-11)?" As Table 1 below illustrates, robots range in autonomy and social interaction, usually increasing from industrial robots to professional service robots to personal service robots.

Industrial robots have been in manufacturingwelding, machining, assembly, packaging, palletising, transportation and material handling-for over half a century (Blackman, 2013; Thrun, 2004). Such robots handle objects from either a stationary platform or sometimes exhibiting mobility (Thrun, 2004; Oborn 2011). In general, industrial robots are stationary rather than mobile, have little social interaction and are semi-autonomous thanks to programming.

Table 1. Robot Types and Characteristics

\begin{tabular}{|c|c|c|c|}
\hline & Industrial & Professional Service & Personal Service \\
\hline Existence & $\sim 50$ years & $\sim 20$ years & $\sim 20$ years \\
\hline Applications & Manufacturing & $\begin{array}{l}\text { Remote areas, health care, } \\
\text { aged care, deep water } \\
\text { repairs, mine clearing }\end{array}$ & $\begin{array}{l}\text { Home, recreation; e.g. as } \\
\text { human companions }\end{array}$ \\
\hline Social Interaction & Little to none & Some & Moderate \\
\hline Mobility & Little to none & Some & Moderate \\
\hline Autonomy & $\begin{array}{l}\text { Semi-autonomous: } \\
\text { programming }\end{array}$ & $\begin{array}{l}\text { Semi to somewhat } \\
\text { autonomous: teleoperation } \\
\text { and programming }\end{array}$ & $\begin{array}{l}\text { Somewhat autonomous: } \\
\text { programming and artificial } \\
\text { intelligence }\end{array}$ \\
\hline $\begin{array}{l}\text { Hospitality \& } \\
\text { tourism examples }\end{array}$ & Food preparation & $\begin{array}{l}\text { Room cleaning, heritage } \\
\text { preservation, telepresence } \\
\text { robots at conferences, } \\
\text { medical tourism }\end{array}$ & $\begin{array}{l}\text { Concierge robots in hotels } \\
\text { and visitor centers, } \\
\text { museum guides, airport } \\
\text { and destination greeters }\end{array}$ \\
\hline Projected Growth & Moderate & Strong & Very strong \\
\hline
\end{tabular}


In their infancy, professional service robots are growing at a much faster pace than industrial robots (Thrun, 2004). Such robots operate in inacessible areas such as underwater, nuclear waste sites and the battlefield (Swinson, 1997; Thrun, 2004). In accessible areas, health care (Kavic, 2004; Oborn et al., 2011) and aged care (Beer et al., 2012; Blackman, 2013; Flandorfer, 2012; Wu et al., 2014) are ripe for further professional service robot intrusion. In general, professional service robots are mobile rather than stationary, may have social interaction and are semi-autonomous to somewhat autonomous thanks to teleoperation and programming.

The latest arrival, personal service robots, assist and entertain people in domestic and recreational settings. The fastest growing category, personal service robots were projected to grow tenfold from 2001 to 2005 (Thrun, 2004). Robots in the home and yard, such as floor cleaners and lawn mowers are already an established market category (Blackman, 2013; Sung et al., 2008; Ulrich, Mondada, \& Nicoud, 1997; Vaussard et al., 2014). A recent experimental study in Japan investigated hotel lobby robots as an alternative to information on digital signs (Pan et al., 2015). Similarly, IBM and Hilton Hotels are experimenting with robots as concierges (Higgenbotham, 2016). Of the three robot categories, personal service robots tend to have the most autonomy, and particularly with entertainment, the most social interaction.

\section{Human Robot Interaction (HRI)}

As the Japanese experiment with hotel lobby robots demonstrated-head movement and direct greetings worked best-human-robot interaction (HRI) is an important robotic element (Pan et al., 2015). Drawing on the marketing literature, service dominant logic whereby the firm and customer co-create value seems applicable to HRI (Barnett et al., 2015; Oborn et al., 2011). Rather than a transactional goods logic, drawing on value co-creation and a service dominant logic helps understand the dynamic HRI social environment. For instance in one study, a robot vacuum cleaner became part of the household social fabric and included non-prescribed functions such as watching for fun, demonstrating to others, ascribing a personality or gender, and dressing the vacuum (Sung et al., 2008).

The HRI social environment is an ongoing enigma. User individualism and a sense of belonging may be difficult; robots try to be in charge and could leave users feeling isolated (Barnett et al., 2015; Wu et al., 2014). The ideal robot would behave machine-like in speed and precision, adhere to social norms and maintain human attributes such as empathy, while avoiding mood swings, mistakes and biases (Barnett et al., 2015; Thrun, 2004). Paradoxically, humans can be impolite to robots (Barnett et al., 2015).

HRI research on acceptance of personal service robots, the robot category with the most social interaction, shows mixed and complex relationships with socio-demographics such as age, gender and education (Flandorfer, 2012). Furthermore, experience with technology can attenuate the relationship of socio-demographic factors with acceptance. A mixed methods study-an online survey of 118 respondents and 41 laboratory scenario tests with a robotexamined gender differences in perceptions of robots in society (Wang, 2014). The study failed to find obvious HRI gender differences in stereotypical assumptions, for example, women being more polite to robots than men. Furthermore, a common limitation of much HRI research is studies with small samples and robot-specific applications (Flandorfer, 2012). Thus, that $\mathrm{Wu}$ and colleagues (2014) found that none of their 11 respondents would adopt a personal service robot, applies just to the robot in their study.

\section{Robot Adoption and Implementation}

Almost a century old, diffusion theory provides a base for investigating innovation adoption and implementation, such as a tendency to overestimate the short term and positive implycations of an innovation while underestimating the long-term and negative effects (Rogers, 2003). Similar to most diffusion research, one study found that young, educated and technologically proficient individuals led in the adoption of robotic vacuum cleaners (Sung et al., 2008). Unlike diffusion research showing an inclination for men to lead in adopting innovations, the same study found men as 
likely as women to own the robotic vacuums. Perhaps expectedly, almost half the adopting households owned pets.

Concerning implementation, one study found that households with children were significantly more satisfied with their robotic vacuum cleaner than were households without children (Sung et al., 2008). Anecdotal qualitative findings included the cleaner helping children learn to crawl, robots chasing pets and pets, particularly parrots, riding on the vacuum cleaner. Finally, and again in line with diffusion findings (Rogers, 2003), owning robotic vacuums has a novelty effect. "After novelty effects had worn off, the robot became another cleaning tool with its own flaws" (Vaussard et al., 2014, p. 17).

\section{Results: Hospitality and Tourism Challenges}

Over three decades ago, Andrew (1984) challenged hospitality academics to consider robotics in their classes. Furthermore, he challenged scholars to research five robotic areas: customer acceptance of robots in foodservice, and robots' impacts on the work environment, management training, facility design and bottom line. This conceptual paper extends his challenge to include tourism academics, human robot interaction and a sixth area, robotic design. A brief discussion of incorporating robotics in the classroom precedes the robotic research agenda.

Pedagogically, lectures should incorporate examples of robots-industrial, professional services and personal services-in their assignments, readings and class discussions. For example, what have students read about robots in hospitality and tourism? What type of robots will customers accept, and why? What factors will enhance or dissuade customer acceptance of robots in tourism and hospitality operations? How will robots impact hospitality and tourism finances, such as investments, revenue, expenses and profitability?

Educators could encourage students to follow and perhaps participate in robot competitions (Touretzky, 2010). Two competitions for example, RoboCup@Home and RoCKIn@Home, focus on developing personal service robots for domestic applications such as serving at a cocktail party or navigating a restaurant (Angulo et al., 2015). These robots could have enhanced networking and cognitive abilities to perform socially useful tasks such as cleaning rooms, room/table service and interact with guests. Competitions could also provide opportunities for hospitality and tourism students to collaborate across disciplines such as communication, computer science, engineering, psychology and anthropology.

Research Area 1: Customer acceptance of robots in tourism and hospitality operations

Personal service robots, and somewhat professional service robots, should be the predominant robot categories related to customer acceptance. Accordingly, the cocreation of value (Barnett et al., 2015; Oborn et al., 2011) and accompanying HRI (Beer et al., 2012; Sung et al., 2008; Thrun, 2004; Wu et al., 2014) will influence customer acceptance of robots. Hotels, for example, are exploring customer acceptance of robotic concierges (Higgenbotham, 2016; Pan et al., 2015). The design factors discussed in Research Area 6e.g. robot appearance and movement-are critical to co-creation, $\mathrm{HRI}$ and eventual customer acceptance (BBC, 2014; Martin, 2016; Mori, 1970; Pan et al., 2015; TouréTillery \& McGill, 2015; Ulrich et al., 1997).

Research Area 2: The impact of robotics on tourism and hospitality financial operations Industrial robots in the back of the house and personal service robots in the front of the house should have direct financial effects. Hilton Hotel's robotic concierge, for example, costs around US $\$ 10,000$. Research questions include robotic return on investment (ROI), capital investments, expenses, revenues, leasing versus buying, employee training, and robot maintenance and depreciation. HRI should also play an important role in the financial aspects of robots, particularly personal service robots (Beer et al., 2012; Thrun, 2004). That is, what HRI aspects will increase robotic $\mathrm{ROI}$ ?

Research Area 3: The effect of robotics on the tourism and hospitality workplace

Similar to impacts on financial operations, industrial robots in the back of the house and 
personal service robots in the front of the house should have direct effects on the workplace. For example, will robots eliminate some jobs while creating other jobs? HRI will be important with personal service robots and somewhat with industrial robots (Barnett et al., 2015; Thrun, 2004; Wu et al., 2014). And inevitably, employees will find ways to 'play' with the robots (Sung et al., 2008).

Research Area 4: Robotic impacts on successful tourism and hospitality management skills and training

Given the lack of successful robot implementation, this research area seems nascent. Complementary areas such as information and digital technologies seem a good start for examining what leads to successful tourism and hospitality robotic skills. Given the nascent robot field, and the applied aspects, research into available training would help grow this area. For example, how do Kirkpatrick's (1967) four training levelsreactions, learning, behaviour and resultsalign with robotic training. As well, what MOOCs might apply to robotics in general and in hospitality and tourism (Ryan, HortonTognazzini, \& Williams, 2016)?

Research Area 5: Robotic impacts on tourism and hospitality design and facilities layout

The use of industrial robots in food production could have major implications on designing robot-friendly kitchen layouts. Similarly, professional service robots such as floor cleaners could necessitate re-designing hotel rooms and dining rooms for efficient cleaning (Ulrich et al., 1997; Vaussard et al., 2014). Personal service robots could be the most challenging area, as robot design impacts HRI (Pan et al., 2015; Thrun, 2004; Touré-Tillery \& McGill, 2015; Ulrich et al., 1997; Wu et al., 2014).

\section{Research Area 6: Robotic designs in hospitality and tourism}

Regardless of the robot-industrial, professional or personal service-type, robot design must be cost effective (Blackman, 2013). Design challenges include dynamic navigation, simple set-up, object/human recognition and manipulation, HRI, cognition and ambient intelligence (Angulo et al., 2015). HRI, a common theme in these six research questions, includes communication-e.g., voice, haptic, visual and programming-and anthropomorphic outcomes (Belk, 2016).

Robot design seems particularly important for personal service robots. For example, the Uncanny Valley Theory (Mori, 1970) posits that as robots become more human like, the human emotional response gets more positive, to a point. Eventually, if the robot is nearly human, the emotional response is highly positive. The problem lies in the in-between-zone, the uncanny valley. Robotic design challenges include dynamic navigation, simple set-up, object recognition and manipulation, human recognition, HRI, cognition and ambient intelligence (Angulo et al., 2015).

\section{Conclusions}

The academic literature seems to have ignored that robots have leaped from science fiction to hotels (Martin, 2016). Now is the time to consider robots-industrial, professional service and personal service-in classrooms, businesses and research (Brynjolfsson et al., 2014; Thrun, 2004; Touretzky, 2010). The revolutionary aspects of robotics will challenge managers to integrate robots into an already complex service system involving employees, customers, suppliers, food processing and both physical and information technology infrastructure.

Likewise academic theory, such as consumer behavior (marketing) and employee behavior (human relations), tends to inform only about human actors. Theory (Beer et al., 2012; Thrun, 2004) and research (Pan et al., 2015; Sung et al., 2008; Vaussard et al., 2014; Wu et al., 2014) should increasingly encompass nonhuman agents. In addition, diffusion theory (Rogers, 2003) should help ground sanguine robotic prognostications and underscore the need for affordable, adoptable and usable robots (Angulo et al., 2015).

This conceptual paper has just scratched the surface of robots in general, and in tourism and hospitality. Furthermore, a major limitation of this study is that robots are evolving quickly (Brynjolfsson et al., 2014; Swinson, 1997; Thrun, 2004; Touretzky, 2010). Other than rapid improvement and applications, the future 
of robots is difficult to predict. Hospitality and tourism academics have the opportunity to position students, industry and themselves at the forefront of the robotic era.

Acknowledgment: This is an updated version of an ENTER 2017 research note and a noncopyrighted 2016 APacCHRIE manuscript.

\section{References}

Ackerman, E. (2014, 15 May). Panasonic Revives Hospital Delivery Robot. IEEE Spectrum, retrieved 22 July, 2016, from http://spectrum.ieee.org/automaton/rob otics/medical-robots/panasonic-hospital -delivery-robot

Andrew, W. P. (1984). Hospitality Education and the Technological Revolution. Journal of Hospitality \& Tourism Research, 8(2), 15-21.

Angulo, C., Pfeiffer, S., Tellez, R., \& Alenyà, G. (2015). Evaluating the Use of Robots to Enlarge AAL Services. Journal of Ambient Intelligence and Smart Environments, 7(3), 301-313.

Barnett, W., Foos, A., Gruber, T., Keeling, D., Keeling, K., \& Nasr, L. (2015, August 25-29, 2014). Consumer Perceptions of Interactive Service Robots: A ValueDominant Logic Perspective. Paper presented at the AMS World Marketing Congress 18, July 14-18, Bari, Italy.

BBC. (2014). China Restaurant Introduces Robot Waiters. BBC News, retrieved 16 July, 2016, from http://www.bbc. com/news/world-asia-30460737.

Beer, J. M., Fisk, A. D., \& Rogers, W. A. (2012). Toward a Psychological Framework for Levels of Robot Autonomy in Human-Robot Interaction. Human Factors and Aging Laboratory Technical Reports. Atlanta, GA: Georgia Institute of Technology, School of Psychology - Human Factors and Aging Laboratory.

Belk, R. (2016). Understanding the robot: Comments on Goudey and Bonnin (2016). Recherche et Applications en Marketing (English Edition), 31(4), 8390.

Blackman, T. (2013). Care Robots for the Supermarket Shelf: A Product gap in
Assistive Technologies. Ageing \& Society, 33(5), 763-781.

Brynjolfsson, E., McAfee, A., \& Cummings, J. (2014). The Second Machine Age: Work, Progress, and Prosperity in a Time of Brilliant Technologies. New York, NY: W. W. Norton \& Company.

Calderone, L. (2013). Robotics in Law Enforcement. Robotics Tomorrow, retrieved November 12, 2016, from http://www.roboticstomorrow.com/articl e/2013/03/robotics-in-lawenforcement/132/

Čapek, K. (2001). Rossum's Universal Robots (P. P. Selver, Nigel, Trans.): Dover Publications.

Collier, D. A. (1983). The Service Sector Revolution: The Automation of Services. Long Range Planning, 16(6), 10-20.

Collier, J. E., \& Bienstock, C. C. (2006). Measuring Service Quality in eretailing. Journal of Service Research, 8(3), 260-275.

Fassnacht, M., \& Koese, I. (2006). Quality of Electronic Services. Journal of Service Research, 9(1), 19-37.

Flandorfer, P. (2012). Population Ageing and Socially Assistive Robots for Elderly Persons: The Importance of Sociodemographic Factors for User Acceptance. International Journal of Population Research, Article ID 829835.

Glende, S., Conrad, I., Krezdorn, L., Klemcke, S., \& Krätzel, C. (2015). Increasing the Acceptance of Assistive Robots for Older People Through Marketing Strategies Based on Stakeholder Needs. International Journal of Social Robotics, 8(3),1-15.

Higgenbotham, S. (2016). This Robot Aims to Improve Your Hotel Stay, Fortune Magazine, Retrieved 12 November, 2016, from http://fortune.com/2016/03/ 09/hilton-robot-ibm-watson/.

Kavic, M. S. (2004). Robotics, Technology, and the Future of Surgery. Journal of the Society of Laparoendoscopic Surgeons, 4(4), 277-279.

Kim, S. J., Wang, R. J.-H., \& Malthouse, E. C. (2015). The Effects of Adopting and Using a Brand's Mobile Application on Customers' Subsequent Purchase 
Behavior. Journal of Interactive Marketing, 31(August), 28-41.

Kirkpatrick, D. L. (1967). Evaluation of Training. In R. L. Craig \& L. R. Bittel (Eds.), Training and Development Handbook (pp. 87-112). New York: McGraw-Hill.

Lam, J. (2015). Robots Are Ready and Welcome to Assist the Elderly. South China Morning Post, retrieved November 12, 2016, from http://www.scmp.com/native/tech/topics /premier-living/article/1867828/robotsare-ready-and-welcome-assist-elderly.

Lam, S. Y., \& Shankar, V. (2014). Asymmetries in the Effects of Drivers of Brand Loyalty Between Early and Late Adopters and Across Technology Generations. Journal of Interactive Marketing, 28(1), 26-42.

Martin, H. (2016). Robots Deliver Fun with Hotel Room Service Orders, and They Don't Expect a Tip. The Los Angeles Times, Retrieved June 18, 2016, from http://www.latimes.com/business/la-fihotel-robots-20160207-story.html.

Mori, M. (1970). The Uncanny Valley. Energy, 7(4), 33-35.

Oborn, E., Barrett, M., \& Darzi, A. (2011). Robots and Service Innovation in Health Care. Journal of Health Services Research \& Policy, 16(1), 46-50.

Pan, Y., Okada, H., Uchiyama, T., \& Suzuki, K. (2015). On the Reaction to Robot's Speech in a Hotel Public Space. International Journal of Social Robotics, 7(5), 911-920.

Parasuraman, A., Zeithaml, V. A., \& Malhotra, A. (2005). E-S-QUAL: A Multiple-Item Scale for Assessing Electronic Service Quality. Journal of Service Research, 7(3), 213-233.

Rogers, E. M. (2003). Diffusion of Innovations (Fifth ed.). New York, New York: Simon \& Schuster.

Rust, R. T., \& Kannan, P. K. (2003). E-Service: A New Paradigm for Business in the Electronic Environment. Communications of the ACM, 46(6), 37-42.

Ryan, P., Horton-Tognazzini, L., \& Williams, A. (2016). A Snapshot of MOOCs in Hospitality and Tourism. Journal of Hospitality \& Tourism Education, 28(2), 107-112.
Sung, J.-Y., Grinter, R. E., Christensen, H. I., \& Guo, L. (2008). Housewives or Technophiles? Understanding Domestic Robot Owners. Paper presented at the International Conference on Human Robot Interaction.

Swinson, M. L. (1997). Battlefield Robots for Army XXI. Carlisle College, Pennsylvania: U.S. Army War College. retrieved 1 November, 2016 from http://www.dtic. mil/dtic/tr/fulltext/u2/a331848.pdf.

Thrun, S. (2004). Toward a Framework for Human-Robot interaction. HumanComputer Interaction, 19(1), 9-24.

Touré-Tillery, M., \& McGill, A. L. (2015). Who or What to Believe: Trust and the Differential Persuasiveness of Human and Anthropomorphized Messengers. Journal of Marketing, 79(4), 94-110.

Touretzky, D. S. (2010). Preparing Computer Science Students for the Robotics Revolution. Communications of the ACM, 53(8), 27-29.

Ulrich, I., Mondada, F., \& Nicoud, J.-D. (1997). Autonomous Vacuum Cleaner. Robotics and Autonomous Systems, 19(3), 233-245.

Vaussard, F. C., Fink, J., Bauwens, V., Rétornaz, P., Hamel, D., Dillenbourgh, P., \& Mondada, F. (2014). Lessons Learned from Robotic Vacuum Cleaners Entering in the Home Ecosystem. Robotics and Autonomous Systems, 62(3), 376-391.

Walley, P., \& Amin, V. (1994). Automation in a Customer Contact Environment. International Journal of Operations \& Production Management, 14(5), 86-100.

Wang, Y. (2014). Gendering Human-Robot Interaction: Exploring How a Person's Gender Impacts Attitudes Toward and Interaction with Robots. (Master of Science), The University of Manitoba, Winnepeg, Manitoba, Canada.

Wu, Y.-h., Wrobel, J., Cornuet, M., Kerhervé, H., Damnée, S., \& Rigaud, A.-S. (2014). Acceptance of an Assistive Robot in Older Adults: A Mixed-method Study of Human-robot Interaction over a 1-month Period in the Living Lab Setting. Clinical Interventions in Aging, 9(May), 8011-8811. 